\title{
Fasting Gastric Acidity Evidential Effect on Esophageal Mucosal Damage
}

\author{
Achnes Pangaribuan ${ }^{1}$, Iga Suryadarma ${ }^{2}$, Wira Gotera ${ }^{2}$ \\ pangaribuan2002@gmail.com \\ ${ }^{1}$ Internal Medicine Study Program, Faculty of Medicine, Udayana University/Sanglah Hospital \\ Denpasar, Indonesia \\ ${ }^{2}$ Internal Medicine Department / KSM, Faculty of Medicine, Udayana University/Sanglah \\ Hospital Denpasar, Indonesia
}

Received: January 19, 2021

Received in Revised: February 20, 2021

Accepted: March 5, 2021

\begin{abstract}
Gastric substances that potentially increase the esophageal mucosal damage are gastric acid, pepsin, bile salts, and pancreatic enzymes. From all of these substances, the highest potential for reflux damage is gastric acid. Although the main cause of clinical symptoms of GERD is acid reflux, it has been known that there are subgroups with typical reflux symptoms that do not provide sufficient response or not responsive to PPI treatment. Despite the improvement of esophagitis, there are no clinical improvements in reflux symptoms of $30 \%$ of respondents. Therefore, this study was designed to determine fasting gastric acidity with endoscopic findings in patients with GERD. A comparative-analysis study, which determines the fasting gastric acidity from endoscopic findings in patients with GERD. Samples recruited using the consecutive sampling technique and divided into groups of esophagitis and non-esophagitis reflux. A total of 40 samples were involved in this study. The Mann-Whitney test was used for analyzing the difference between fasting gastric acidity from endoscopic findings of esophagitis lesions in a patient with GERD. The median value for fasting gastric acidity in the esophagitis reflux group was $1.88(0.82-4.84)$, whereas the median value for fasting gastric acidity in the non-esophagitis reflux group was 2.49 (0.68-5.97). The Mann-Whitney test result was $\mathrm{p}=0.298$ ( $\mathrm{p}>0.05)$. This study shows that there is no significant difference in fasting gastric acidity from endoscopic findings between esophagitis and nonesophagitis reflux groups in patients with gastroesophageal reflux disease (GERD). This study shows that esophagitis lesions are not affected by gastric acidity.
\end{abstract}

Keywords: Gastroesophageal Reflux Disease (GERD), Esophagitis, Non-Esophagitis, Refluxat, Fasting Gastric Acidity

\section{Introduction}

The pathogenesis of GERD is very complex and multifactorial. GERD occurs due to an imbalance between the offensive and defensive factors of the esophageal mucosal defense systems and gastric reflux substances. Gastric substances that potentially increase the esophageal mucosal damage are gastric acid, pepsin, bile salts, and pancreatic enzymes. From all of these substances, the highest potential for reflux damage is gastric acid. A pH level less than 4 has been defined as a margin in which gastric reflux able to injure the esophagus. Ayazi et al., 2009) confirmed that there is a clear inverse relationship between fasting gastric acidity and esophageal acid exposure. There is an 
inverse correlation between the escalation of fasting gastric $\mathrm{pH}$ and the total percentage of time esophageal $\mathrm{pH}$ less than 4.

In recent years, gastric acid has been shown to play a major role in GERD pathogenesis and proton pump inhibitors (PPIs) are the first choice treatment in GERD patients. Although the main cause of clinical symptoms of GERD is acid reflux, it has been known that there are subgroups with typical reflux symptoms that do not provide sufficient response or not responsive to PPIs treatment. Despite the improvement of esophagitis, there are no clinical improvements in reflux symptoms of $30 \%$ of respondents (Sifrim \& Zerbib, 2012; Richter, 2009). This result shows that acid reflux is not a major cause of GERD. To test the hypothesis, we designed a study to determine fasting gastric acidity between esophagitis and non-esophagitis reflux from endoscopic findings.

\section{Methods}

This study was conducted using a comparative-analysis study. The sample population consisted of GERD patients who visited/came for control visits at the Gastroenterology Division of the Department of Internal Medicine of the Faculty of Medicine of the Udayana University/Sanglah Public Hospital from September 2019 until March 2020. A total of 40 GERD patients, which were confirmed with GERD questionnaire (GERD-Q) $\geq 8$ and fulfilled inclusion and exclusion criteria, were recruited with consecutive sampling technique. Upper gastrointestinal endoscopy concomitant with measurement of fasting gastric acidity was performed after at least 24 hours without acid-suppressive medication. In view of the need for more diagnostic accuracy of esophageal mucosal damage, a high definition endoscopy coupled with narrow-band imaging (NBI) was performed. Furthermore, esophagitis reflux is classified according to the Los Angeles classification. The measurement of fasting gastric acidity is done with a digital $\mathrm{pH}$ meter ( $\square$ TRIMETER). Statistical analyzes were performed using SPSS 20. (Windows version; SPSS Inc, Chicago [IL], USA). The Mann-Whitney test was used for analyzing the difference between fasting gastric acidity from endoscopic findings of esophagitis lesions in patient with GERD.

\section{Results and Discussion}

A total of 40 subjects recruited in this study, which were divided into esophagitis reflux and nonesophagitis reflux. In addition, there were higher number of females participants than males, with the percentage $72,5 \%$ (29 subjects) and 27,5\% (11 subjects) respectively, while the average age of both gender was $42.85 \pm 15.84$ years. As seen from the endoscopic result, we found more subjects without hiatal hernia compared to participants with hiatal hernia, with around 80\% (12 subjects) and 20\% (8 subjects) respectively. The median value for fasting gastric $\mathrm{pH}$ in patient with GERD was $2.06(0.68-5.97)$. Moreover, there were $32(80 \%)$ subjects with gastric $\mathrm{pH}<4$ and $8(20 \%)$ with gastric $\mathrm{pH} \geq 4$. In esophagitis reflux group, there were $17(85 \%)$ subjects with gastric $\mathrm{pH}<4$ with the median value of fasting gastric $\mathrm{pH} 1.88(0.82-4.84)$, whereas in non-esophagitis group there were $15(75 \%)$ subjects with gastric $\mathrm{pH}<4$ with the median value for fasting gastric $\mathrm{pH} 2.49$ (0.68-5.97). As a result, the demography characteristic of fasting gastric $\mathrm{pH}$ and esophageal mucosal damage from endoscopic findings can be seen in tabel 1 and table 2 below.

Table 1. Characteristics variables patient with GERD

\begin{tabular}{|c|c|}
\hline Variable & $\mathbf{n}=\mathbf{4 0}$ \\
\hline Sex, $\mathrm{n}(\%)$ & \\
\hline Male & $11(27.5 \%)$ \\
\hline
\end{tabular}




\begin{tabular}{|l|c|}
\hline Female & $29(72.5 \%)$ \\
\hline Age (years), mean \pm SD & $42.85 \pm 15.84$ \\
\hline BMI, mean \pm SD & $22.36 \pm 3.45$ \\
Underweight (BMI < 18.5) & $5(12.5 \%)$ \\
Normal (BMI 18.5-24.9) & $29(72.5 \%)$ \\
Overweight (BMI 25-29.9) & $5(12.5 \%)$ \\
Obese (BMI $\geq 30)$ & $1(2.5 \%)$ \\
GERDQ score, mean \pm SD & $10.68 \pm 1.34$ \\
Hernia hiatal & \\
Present & $8(20 \%)$ \\
Absent & $32(80 \%)$ \\
Fasting gastric pH, median (min-max) & $2.06(0.68-5.97)$ \\
\hline
\end{tabular}

Table 2. Differences in characteristics between ERD dan NERD group

\begin{tabular}{|l|c|c|c|}
\hline \multicolumn{1}{|c|}{ Variable } & ERD & NERD & p value \\
\hline Sex & & & 0,723 \\
Male & $5(25 \%)$ & $6(30 \%)$ & \\
Female & $15(75 \%)$ & $14(70 \%)$ & \\
BMI, mean \pm SD & $22,07 \pm 2,97$ & $22,42 \pm 3,77$ & 0,706 \\
Underweight (BMI < 18,5) & $3(15 \%)$ & $2(10 \%)$ & \\
Normal (BMI 18,5-24,9) & $14(70 \%)$ & $15(75 \%)$ & \\
Overweight (BMI 25-29,9) & $3(15 \%)$ & $2(10 \%)$ & \\
Obese (BMI $\geq 30)$ & $0(0 \%)$ & $1(5 \%)$ & \\
GERDQ score, mean \pm SD & $11,05 \pm 1,05$ & $10,30 \pm 1,52$ & \\
Hernia hiatal & & & 0,114 \\
Present & $6(30 \%)$ & $2(10 \%)$ & \\
Absent & $14(70 \%)$ & $18(90 \%)$ & \\
Gastric $\mathrm{pH}$, median $(\min -\mathrm{max})$ & $1.88(0.82-4.84)$ & $2,49(0,68-5,97)$ & \\
Gastric $\mathrm{pH}<4 / \mathrm{pH} \geq 4$ & $17 / 3$ & $15 / 5$ & 0,429 \\
\hline
\end{tabular}

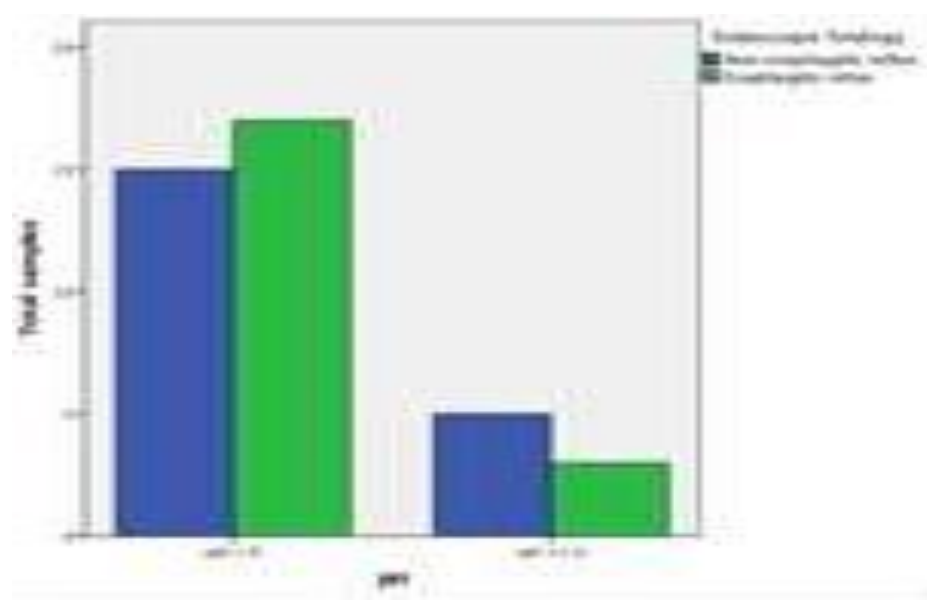


Figure 1. Frequency of fasting gastric $\mathrm{pH}$ determine by $\mathrm{pH}<4$ or $\mathrm{pH} \geq 4$ andendoscopic findings in patient with GERD.

The Mann-Whitney was used to determine fasting gastric acidity between esophagitis and nonesophagitis reflux. The Mann-Whitney test result showed no significant difference, with $\mathrm{p}=0.298$ ( $>>0.05)$.

Tabel 3. Association between fasting gastric $\mathrm{pH}$ in esophagitis and non-esophagitis reflux from endoscopic findings

\begin{tabular}{|l|l|c|c|c|}
\hline & & $\mathrm{n}$ & $\mathrm{pH}$ & $\mathrm{p}$ value \\
\hline Endoscopic findings & NERD & 20 & $2.495(0.68-5.97)$ & $\mathrm{p}=0.298$ \\
& ERD & 20 & $1.88(0.82-4.84)$ & \\
\hline
\end{tabular}

\section{Mann-Whitney test}

In this study we found that the median value for fasting gastric $\mathrm{pH}$ in the esophagitis reflux group was $1.88(0.82-4.84)$, whereas the median value for fasting gastric acidity in the non-esophagitis reflux group was 2.49 (0.68-5.97). The Mann-Whitney test result was $\mathrm{p}=0.298$ ( $\mathrm{p}>0.05)$. The result from this study shows that there is no significant difference of fasting gastric $\mathrm{pH}$ between esophagitis and non esophagitis reflux groups (GERD) from endoscopic findings. This study shows that esophagitis lesions are not affected by fasting gastric $\mathrm{pH}$. Therefore, this result was similar with several previous studies.

Boeckxstaens \& Smout. (2010) a metanalysis study suggested that the proportions of reflux episodes are acidic $(\mathrm{pH}<4)$, weak acidic $(\mathrm{pH} \mathrm{4-7)}$ and weak alkaline $(\mathrm{pH}>7)$ in adult patients with GERD, in order to evaluate their correlation with symptoms, this study stated that the proportion of acid reflux episodes did not differ between patients without reflux esophagitis and those who had reflux esophagitis. The same result was obtained by Bredennoord et al., (2006) comparing the characteristics of reflux episodes from the control group, NERD and patients with varying degrees of oesophagitis and Barrett's esophagus, also stated that the proportion of total reflux episodes that were acidic, weak and alkaline were similar in each group and only had slight variation between controls, NERD, reflux esophagitis and Barrett's esophagus.

Hirschowitz (1991) stated that there was no significant increase in gastric basal acid output (BAO), stimulated gastric acid secretion and maximum gastric acid secretion (MAO) against esophagitis lesions. Zhu et al. (1998) assessed the relationship between BAO and esophagitis lesions in patients with GERD, only esophagitis and reflux esophagitis with duodenal ulcer proved that there is no parallel relationship between $\mathrm{BAO}$ and the severity of esophagitis reflux with or without duodenal ulcer, suggesting that BAO is not a major pathogenetic factor in GERD.

The pathogenesis of GERD is very complex and not fully understood. The mechanism when reflux episodes become clinically manifested is determined by duration and volume of the reflux, the ability of the esophagus to neutralize refluxat with bicarbonate from saliva, and the degree of acid reflux Tack \& Pandolfino, 2018). However, some important questions remain unanswered. For instance, in some patients with reflux esophagitis (ERD) do not have severe clinical manifestations compared with non-esophagitis (NERD), reflux with normal $\mathrm{pH}$ can cause clinical manifestations in patients with NERD and some patients with ERD experienced remission spontaneously with placebo while in some other patients do not show improvement in esophagitis lesions even after received optimal PPIs therapy. 
Because the severity of esophageal damage cannot be predicted based on the amount of time acid contacts the esophageal mucosa, nor can the $\mathrm{pH}$ of esophageal refluxate predict the severity of symptoms, researchers have proposed that factors other than the acidity of refluxate or the amount and duration of exposure to refluxate might determine esophageal damage. Several studies demonstrate mucosal resistance, inflammation, and free radical damage are major determinants in the progression of reflux esophagitis (Patrick, 2011). In studies with animal models, oxidative stress has more relevant role than acid exposure in the pathogenesis of esophageal ulceration. This study stated that the administration of ethanol extracted from artemisia asiatica as an antioxidant is more effective to prevent the erosion of esophagus compared to ranitidine (Oh et al., 2001). Therefore, it explains that immunologic response played a bigger role than caustatic injury.

\section{Conclusion}

Finally, the result of this study provides a strong evidence that esophageal mucousal damage is not affected by gastric acidity.

\section{References}

Ayazi, S., Leers, J. M., Oezcelik, A., Abate, E., Peyre, C. G., Hagen, J. A., ... \& Crookes, P. F. (2009). Measurement of gastric $\mathrm{pH}$ in ambulatory esophageal $\mathrm{pH}$ monitoring. Surgical endoscopy, 23(9), 1968-1973.

Sifrim, D., \& Zerbib, F. (2012). Diagnosis and management of patients with reflux symptoms refractory to proton pump inhibitors. Gut, 61(9), 1340-1354.

Richter, J. E. (2009). Role of the gastric refluxate in gastroesophageal reflux disease: acid, weak acid and bile. The American journal of the medical sciences, 338(2), 89-95.

Boeckxstaens, G. E., \& Smout, A. (2010). Systematic review: role of acid, weakly acidic and weakly alkaline reflux in gastro-oesophageal reflux disease. Alimentary pharmacology \& therapeutics, 32(3), 334-343.

Bredenoord, A. J., Weusten, B. L., Curvers, W. L., Timmer, R., \& Smout, A. J. (2006). Determinants of perception of heartburn and regurgitation. Gut, 55(3), 313-318.

Hirschowitz, B. I. (1991). A critical analysis, with appropriate controls, of gastric acid and pepsin secretion in clinical esophagitis. Gastroenterology, 101(5), 1149-1158.

Zhu, H. M., Huang, X., Deng, C. Z., Porro, G. P., Pace, F., \& Sangaletti, O. (1998). Pathogenetic factors affecting gastroesophageal reflux in patients with esophagitis and concomitant duodenal ulcer: a multivariate analysis. World journal of gastroenterology, 4(2), 153.

Tack, J., \& Pandolfino, J. E. (2018). Pathophysiology of gastroesophageal reflux disease. Gastroenterology, 154(2), 277-288.

Patrick, L. (2011). Gastroesophageal reflux disease (GERD): a review of conventional and alternative treatments. Alternative Medicine Review, 16(2).

Oh, T. Y., Lee, J. S., Ahn, B. O., Cho, H., Kim, W. B., Kim, Y. B., ... \& Hahm, K. B. (2001). Oxidative stress is more important than acid in the pathogenesis of reflux oesophagitis in rats. Gut, 49(3), 364-371. 